\title{
Aggregation, Complaints, and Risk
}

\author{
Joe Horton
}

\section{Introduction}

Many of our acts benefit some people and burden others. According to some moral views, when all other things are equal, we are morally required to act in the way that maximizes the sum of benefits minus burdens. ${ }^{1}$ We can say that these views are aggregative. The bestknown aggregative view is Utilitarianism, but there are others. ${ }^{2}$

Aggregative views tend to have counterintuitive implications in cases in which we must choose between imposing large burdens on each of a few people and imposing small burdens on each of many. ${ }^{3}$ T. M. Scanlon offers the following illustration. ${ }^{4}$

For helpful comments and discussion, I am grateful to Renee Jorgensen Bolinger, David Boonin, Alexander Dietz, Nathan Robert Howard, Nicola Kemp, Nicholas Laskowski, Alexander Sarch, Thomas Sinclair, Anthony Taylor, Jonathan Wright, and the editors at Philosophy \& Public Affairs. I am especially grateful to Abelard Podgorski, Jonathan Quong, Jacob Ross, Mark Schroeder, and Ralph Wedgwood.

${ }^{1}$ The "all other things equal" clause allows these views to accommodate moral constraints. See Robert Nozick, Anarchy, State, and Utopia (Hoboken, NJ: Blackwell, 2003), pp. 28-30.

${ }^{2}$ For example, Prioritarianism. See Derek Parfit, "Equality and Priority,” Ratio 10 (1997): 202-21.

${ }^{3}$ We might try to avoid these implications by arguing that the different burdens are incommensurable. See James Griffin, Well-Being: Its Meaning, Measurement, and Moral Importance (Oxford: Oxford University Press, 1989), pp. 75-92. However, this move leads to other problems. See Alastair Norcross, “Comparing Harms: Headaches and Human Lives," Philosophy \& Public Affairs 26 (1997): 135-67; and Larry Temkin, Rethinking the Good: Moral Ideals and the Nature of Practical Reasoning (Oxford: Oxford University Press, 2012), pp. 45-52.

${ }^{4}$ T. M. Scanlon, What We Owe to Each Other (Cambridge, Mass.: Harvard University Press, 1998), p. 235. 
Transmitter Room: Jones has suffered an accident in a TV broadcasting station and is receiving extremely painful electric shocks. If you turn off the power, a huge number of viewers will miss the second half of the World Cup final.

Intuitively, you are morally required to turn off the power, no matter how many viewers there are. But aggregative views imply that, if there are enough viewers, you are morally required to leave the power on, for the burden imposed on Jones will be less than the sum of the burdens that would be imposed on each of the viewers.

Scanlon suggests that what matters in Transmitter Room is not the sum of benefits minus burdens that you could bring about, but rather the strength of the individual complaints that could be made against your act. Jones could make a much stronger individual complaint against you leaving the power on than any of the viewers could make against you turning the power off. That seems to be why you are morally required to turn the power off, no matter how many viewers there are.

This line of reasoning has led Scanlon and many other philosophers to reject aggregative views and accept some version of what we can call Minimax Complaint, or MC. According to this view, when we would not be violating any moral constraints, we are morally required to act in the way that minimizes the strongest individual complaint. ${ }^{5}$

\footnotetext{
${ }^{5}$ Scanlon, What We Owe to Each Other, chap. 5. Scanlon's view departs from the simple version of MC in three main ways. First, his view is concerned not directly with acts, but rather with principles that regulate acts. Second, on his view, "a person could reasonably reject a principle on the grounds that it treated him or her unfairly." Third, on his view, "principles must be considered within the framework of other principles which are, for the moment, being held constant, and possible grounds for rejection are shaped by these background principles.” See p. 229. As far as I can tell, these departures from the simple version of MC do not protect Scanlon's view from the objections that I raise below. For further defense and discussion of MC, see T. M. Scanlon, "Contractualism and Utilitarianism," in Utilitarianism and Beyond, ed. Amartya Sen and Bernard
} 
In sections 2 through 5, I argue that MC must be rejected because it has implausible implications in certain cases involving risk. In these cases, we can apply MC either ex ante, by focusing on the complaints that could be made based on the prospects that an act gives to people, or ex post, by focusing on the complaints that could be made based on the actual results that an act has for people. I argue that MC has implausible implications either way. ${ }^{6}$ It might seem unnecessary to offer a new argument against $\mathrm{MC}$, since there is an obvious objection to this view. According to this objection, $\mathrm{MC}$ has the implausible implication that we are morally required to save one person from a large burden, such as death, rather than any number of people from a slightly smaller burden, such as permanent paralysis. But proponents of MC are not persuaded by this objection. They argue that MC can be modified to permit the aggregation of complaints whenever opposing complaints are, as

Williams (Cambridge: Cambridge University Press, 1982), pp. 103-28; Thomas Nagel, Mortal Questions (Cambridge: Cambridge University Press, 2012), chap. 8; Thomas Nagel, Equality and Partiality (Oxford: Oxford University Press, 1991); Sophia Reibetanz, “Contractualism and Aggregation,” Ethics 108 (1998): 296311; Michael Otsuka, "Saving Lives, Moral Theory, and the Claims of Individuals," Philosophy \& Public Affairs 34 (2006): 109-35; Aaron James, “Contractualism’s (Not So) Slippery Slope,” Legal Theory 18 (2012): 263-92; Alex Voorhoeve, “How Should We Aggregate Competing Claims?,” Ethics 125 (2014): 64-87; Rahul Kumar, "Risking and Wronging," Philosophy \& Public Affairs 43 (2015): 27-51; Michael Otsuka, "Risking Life and Limb,” in Identified Versus Statistical Lives, ed. I. Glenn Cohen, Norman Daniels, and Nir Eyal (Oxford: Oxford University Press, 2015), pp. 77-93; and Johann Frick, "Contractualism and Social Risk," Philosophy \& Public Affairs 43 (2015): 175-223.

\footnotetext{
${ }^{6}$ For a defense of the view that we should apply MC ex ante, see James, “Contractualism's (Not So) Slippery Slope"; Kumar, "Risking and Wronging"; and Frick, "Contractualism and Social Risk." For a defense of the view that we should apply MC ex post, see Scanlon, What We Owe to Each Other, chap. 5; Reibetanz, "Contractualism and Aggregation"; and Otsuka, "Risking Life and Limb." Scanlon has recently switched to the ex ante view, and he credits Frick's paper with changing his mind.
} 
with death and permanent paralysis, sufficiently close in strength. ${ }^{7}$ We can call this modified view Partially Aggregative MC, or PAMC. My objections to MC will also apply to PAMC.

In section 6 , I suggest that cases involving risk will pose serious problems not just for $\mathrm{MC}$, but also for nonaggregative views more generally. I then argue that, in the absence of a viable nonaggregative view, we can plausibly embrace aggregation, despite the counterintuitive implications that aggregative views have in cases like Transmitter Room.

Since complaints were introduced to support antiaggregative intuitions, it might seem that once we embrace aggregation, we should forget about complaints. In section 7, I argue that we should not. Though aggregative views have traditionally focused on the sum of benefits minus burdens, they can also focus on the sum of complaints. And we should prefer those that do, for only they can respect two morally important facts: the separateness of persons and the unity of the individual.

\section{Against Ex Ante MC}

I now begin my critique of MC. Again, I argue that MC must be rejected because, whether we apply it ex ante or ex post, it has implausible implications in certain cases involving risk. In this section, I assume that we should apply MC ex ante, by focusing on the complaints that could be made based on the prospects that an act gives to people. I present two cases, each involving risk, that together illustrate a decisive reason to reject ex ante MC. I then reject a response to this argument suggested by Johann Frick.

\footnotetext{
${ }^{7}$ See F. M. Kamm, Morality, Mortality, vol. 1 (Oxford: Oxford University Press, 1998), pp. 111-19; Scanlon, What We Owe to Each Other, p. 232; and Voorhoeve, "How Should We Aggregate Competing Claims?” For criticisms of this kind of view, see Derek Parfit, "Justifiability to Each Person," Ratio 16 (2003): 368-90; and John Halstead, “The Numbers Always Count,” Ethics 126 (2016): 789-802. Alex Voorhoeve replies to these criticisms in "Why One Should Count Only Claims with Which One Can Sympathize," Public Health Ethics (forthcoming).
} 


\section{II.A. The Main Objection to Ex Ante MC}

Suppose that in

Villain 1: A villain has kidnapped two children, $\mathrm{C} 1$ and $\mathrm{C} 2$. He will either (1) cut one hand off $\mathrm{C} 1$, or (2) run a lottery that gives $\mathrm{C} 2$ a one-in-a-billion chance of death. You must choose which.

I take it that you are morally required to choose (2), imposing a tiny chance of death on $\mathrm{C} 2$ to spare $\mathrm{C} 1$ from losing a hand. ${ }^{8}$ For ex ante MC to capture this judgment, a complaint against certainly losing a hand must be stronger than a complaint against a one-in-a-billion chance of death.

Suppose next that in

Villain 2: A villain has kidnapped $\mathrm{C} 1$ and ten billion other children. He will either (1) cut one hand off $\mathrm{C} 1$, or (2) randomly select and kill ten of the other children. You must choose which.

Clearly, you are morally required to choose (1), imposing the loss of a hand on C1 to spare ten other children from death. But ex ante MC implies otherwise. If you choose (2), though you ensure that ten of the ten billion children will die, you impose on each of these children only a one-in-a-billion chance of death. We have just seen that a complaint against certainly losing a hand is stronger than a complaint against a one-in-a-billion chance of death. So C1

\footnotetext{
${ }^{8}$ It might be claimed that you should refuse to make a choice, for then your hands are clean. To block this response, we can suppose that if you refuse to make a choice, the villain will destroy the world.
} 
has a stronger complaint against (1) than any of the other children has against (2). So ex ante MC has the implausible implication that you are morally required to choose (2). ${ }^{9}$

The more general problem is this: ex ante MC has the implausible implication that we are morally required to do what we know will be very bad for many people rather than what we know will be much less bad for a few people whenever we have sufficiently low credence about who the former people are.

Notice that this objection cannot be avoided by appeal to PAMC. A complaint against certainly losing a hand is much stronger than a complaint against a one-in-a-billion chance of death. Since these complaints are not close in strength, PAMC cannot allow us to aggregate the ten billion complaints against a one-in-a-billion chance of death in a way that might outweigh the complaint against losing a hand. So ex ante PAMC has the same implication as ex ante MC.

Why do these views fail to capture our intuitions about cases like Villain 2, where a risk is dispersed across a very large group of people? I suggest that the root of the problem is the restriction on aggregation and, more specifically, the refusal to allow that many small risks can combine to morally outweigh a much larger individual burden. But before we accept that diagnosis, we should consider some other possibilities.

\section{II.B. Frick's Pluralist Response}

In response to a related objection to ex ante MC, Johann Frick suggests "scaling back the ambitions" of MC. ${ }^{10}$ Rather than accepting MC as a view about what we are morally required to do all things considered, we could accept it as a view about one category of pro tanto moral reasons. According to this scaled-back version of the view, which we can call

\footnotetext{
${ }^{9}$ A similar objection is presented in Reibetanz, "Contractualism and Aggregation," pp. 302-3.

${ }^{10}$ Frick, "Contractualism and Social Risk," pp. 212-23.
} 
MCweak, when every alternative to an act would produce a stronger individual complaint, this gives us a pro tanto moral reason to perform this act. As Frick emphasises, this pro tanto moral reason could be outweighed by other pro tanto moral reasons, such as those deriving from aggregative considerations or from consequentialist considerations about the goodness of outcomes.

MCweak can avoid the objection that I pressed against ex ante MC. Recall Villain 2.

Villain 2: A villain has kidnapped $\mathrm{C} 1$ and ten billion other children. He will either (1) cut one hand off $\mathrm{C} 1$, or (2) randomly select and kill ten of the other children. You must choose which.

MCweak implies only that you have a pro tanto moral reason to choose (2). It is plausible that this complaints-based moral reason is outweighed by the aggregative and consequentialist moral reasons in favor of choosing (1). Thus, MCweak is compatible with the claim that you are morally required to choose (1).

But MCweak is vulnerable to a closely related objection. Suppose that in

Villain 3: A villain has kidnapped C1 and one billion other children. He will either (1) break three of C1's fingers, or (2) randomly select one of the other children and break four of his fingers. You must choose which.

I take it that you are morally required to choose (1), imposing three broken fingers on $\mathrm{C} 1$ to spare another child from four broken fingers. But you have a very strong complaints-based reason to choose (2), since a complaint against certainly having three fingers broken is much stronger than a complaint against a one-in-a-billion chance of having four fingers broken, and 
you have only a very weak consequentialist reason to choose (1), since an outcome in which one child has four fingers broken is only slightly worse than an outcome in which one child has three fingers broken. So for MCweak to yield the intuitively correct result in this case, we must claim that even a very strong complaints-based reason is outweighed by even a very weak consequentialist reason. And once we allow that, accepting MCweak will make no difference, or only a very slight difference, to what we are morally required to do.

It is worth considering a slight revision to Villain 3. Suppose that the villain will either (1) break three of C1's fingers, or (2) randomly select one of the other children and break three (rather than four) of his fingers. It seems to me that you have equal moral reasons to choose each option. If that is right, MCweak is not just inconsequential, but also false, for it implies that you have an extra complaints-based moral reason to choose (2).

\section{What Is Ex Post MC?}

In the previous section, I assumed that we should apply MC ex ante, by focusing on the complaints that could be made based on the prospects that an act gives to people. As I have said, there is an alternative. We might instead apply MC ex post, by focusing on the complaints that could be made based on the actual results that an act has for people. In this section, I try to clarify this idea, and I explain how it avoids the objection that I pressed against ex ante MC. In the next section, I argue that ex post MC must be rejected, because there are other cases involving risk in which it has implausible implications.

\section{III.A. Moreau's Proposal}

Recall Villain 2. 
Villain 2: A villain has kidnapped $\mathrm{C} 1$ and ten billion other children. He will either (1) cut one hand off $\mathrm{C1}$, or (2) randomly select and kill ten of the other children. You must choose which.

Sophia Moreau (formerly Sophia Reibetanz) suggests that, in this kind of case, it is a mistake to simply apply MC ex ante. ${ }^{11}$ She writes,

As long as we know that acceptance of a principle [directing us to perform some act] will affect someone in a certain way, we should assign that person a complaint that is based upon the full magnitude of the harm or benefit, even if we cannot identify the person in advance. It is only if we do not know whether acceptance of a principle will affect anyone in a certain way that we should allocate each individual a complaint based upon his expected harms and benefits under that principle.

On this proposal, because we know that, if you choose (2), ten children will die, we should assign ten children a complaint against certainly dying. Since this complaint is stronger than $\mathrm{C} 1$ 's complaint against certainly losing a hand, given this proposal, $\mathrm{MC}$ implies that you are morally required to choose (1), which is clearly the right result.

Moreau's proposal is sometimes taken to be a statement of the view that we should apply MC ex post. ${ }^{12}$ But there are at least two problems with her proposal.

First, on Moreau's proposal, it is often mysterious both whom we are assigning complaints to and why we are assigning these complaints to anyone. For example, in Villain 2, Moreau's proposal directs us to assign a complaint against certainly dying to ten of the ten

\footnotetext{
${ }^{11}$ Reibetanz, “Contractualism and Aggregation,” p. 304.

${ }^{12}$ See, for example, Frick, "Contractualism and Social Risk," p. 185.
} 
billion children. But which ten children should we assign this complaint to? And why should we assign this complaint to any of them, when none of them actually faces certain death? (I return to these questions in the next subsection.)

Second, on Moreau's proposal, it is only when we know that an act will burden someone in some way that we should assign this person a complaint based upon the full magnitude of the burden. If we do not know how an act will affect people, we are to "allocate each individual a complaint based upon his expected harms and benefits." This feature of the proposal leaves it vulnerable to a version of the objection that I pressed against ex ante MC. Suppose that in

Villain 4: A villain has kidnapped $\mathrm{C} 1$ and one hundred billion other children. He will either (1) cut one hand off $\mathrm{C} 1$, or (2) randomly select two hundred of the other children and then flip a coin to decide whether to kill them. You must choose which.

I take it that you are morally required to choose (1), imposing the loss of a hand on C1 rather than risking the lives of two hundred children on a coin flip. But even on Moreau's proposal, MC implies otherwise. If you choose (2), there is a one-in-two chance that no one will die. Since we do not know whether anyone will die, on Moreau's proposal, we should assign each of the one hundred billion children a complaint "based upon his expected harms and benefits." And that means assigning each of these children a complaint against a one-in-abillion chance of death. Since a complaint against certainly losing a hand is stronger than a complaint against a one-in-a-billion chance of death, it follows that $\mathrm{C} 1$ has a stronger 
complaint against (1) than any of the other children has against (2). So even on Moreau's proposal, MC has the implausible implication that you are morally required to choose (2). ${ }^{13}$

\section{III.B. Otsuka's Proposal}

Michael Otsuka suggests a way of extending Moreau's proposal. ${ }^{14}$ He writes,

[Suppose] we do not know that anyone would end up with a complaint of premature death in [some] scenario, but we are $95 \%$ certain that someone would end up with such a complaint. I propose that, rather than following [Moreau's] advice [by assigning each person a complaint "based upon his expected harms and benefits"], we should instead posit a complaint of premature death in this scenario, where this complaint is discounted in a manner that tracks the probability that someone would suffer this fate. When applied to the scenario in question, there would be the following case against being exposed to risk. There is a $95 \%$ chance that someone would be killed as the result of such exposure, and a 5\% chance that nobody would be killed. Since the risk of death falls short of certainty ... we should register a strong complaint on behalf of that one victim, whoever in particular he may end up being, who is $95 \%$ certain to exist. But we should discount this complaint by $5 \%$ to reflect the chance that nobody would suffer any harm.

\footnotetext{
${ }^{13}$ We can make this objection even stronger. Suppose that, if you choose (2), the villain will decide whether to kill the two hundred children by running a lottery that favors killing them 90 percent of the time. It now seems even clearer that you are morally required to choose (1). But we still do not know that choosing (2) will result in any deaths, so, on Moreau's proposal, MC still implies that you are morally required to choose (2).

${ }^{14}$ Otsuka, "Risking Life and Limb," p. 88.
} 
Otsuka seems to be suggesting the following way of applying MC. When we know that there is a risk that an act would impose a particular burden on someone, even if we do not know who this someone is, we should posit a complaint against this act based on the full magnitude of this burden, and then discount this complaint by the probability that someone will experience this burden. We are then morally required to act not in the way that minimizes the strongest individual complaint, but rather in the way that minimizes the strongest probabilitydiscounted individual complaint.

As I explain in the next subsection, Otsuka's proposal is not quite the right way to apply MC ex post. But it is on the right track. It gets us the intuitively correct result in each of the cases that we have considered so far. Recall Villain 4.

Villain 4: A villain has kidnapped $\mathrm{C} 1$ and one hundred billion other children. He will either (1) cut one hand off $\mathrm{C} 1$, or (2) randomly select two hundred of the other children and then flip a coin to decide whether to kill them. You must choose which.

On Otsuka's proposal, we reason as follows. If you choose (1), C1 will certainly lose a hand. So we posit a complaint against (1) based on losing a hand and then discount this complaint by the probability that $\mathrm{C} 1$ will actually lose a hand. Since the probability is one, this means not discounting this complaint at all. If you choose (2), there is a one-in-two chance that two hundred children will die. So we posit a complaint against (2) based on death and then discount this complaint by the probability that anyone will actually die. Since the probability is one in two, this means reducing the strength of this complaint by half. We then compare a complaint against losing a hand with a complaint that has half of the strength of a complaint against death. Plausibly, the latter complaint is stronger. So it follows that you are morally required to choose (1), which is clearly the right result. 
Otsuka worries that his proposal suffers from the first problem that I raised for Moreau's proposal. ${ }^{15}$ He notes that on his proposal, we are often required to posit a complaint even though "no particular flesh-and-blood person would have a complaint." The bearer of this complaint, he suggests, is in some respects "akin to a fictional character rather than an actual flesh-and-blood human being." And, he writes, "one might question whether the complaints of such abstract entities, who are other than actual persons, have moral force.” Why should what we are morally required to do be determined in part by "the phantom complaint of a purely abstract entity"?

A possible answer to this question is that, because the universe is largely deterministic, really there is a fact about which person would experience the relevant burden, and so really there is a fact about to whom the corresponding complaint belongs. Otsuka does not appeal to this answer, and rightly so. If his proposal depended on the universe being deterministic, it would not apply in a nondeterministic universe, or in any case in which things are objectively risky. So in a nondeterministic universe, and in any case in which things are objectively risky, we would have to apply MC ex ante. So we would get the intuitively wrong result in versions of my cases in which the villain selects the children using a nondeterministic lottery.

Otsuka's actual answer to this question is brief and opaque. He writes,

I believe that the answer to this question is that the complaint ... is not the complaint of an indeterminate person along the lines of a fictional character. ... Rather the indeterminacy of the person is simply the lack of determinacy to which of the ...

\footnotetext{
${ }^{15}$ Ibid., pp. 84-86.
} 
scenarios would have been the upshot, where each scenario involves the killing of an actual flesh-and-blood [person]. ${ }^{16}$

I am not sure what Otsuka has in mind here. But there is a way of interpreting his proposal on which it avoids the charge of assigning phantom complaints to purely abstract entities. We need to distinguish between ex ante complaints, which are complaints based on the prospects that an act gives to people, and ex post complaints, which are complaints based on the actual results that an act has for people. When we apply MC ex ante, we ignore ex post complaints and aim to minimize the strongest ex ante complaint that could be made against our act. Otsuka's proposal can be seen as directing us, instead, to ignore ex ante complaints and aim to minimize the strongest ex post complaint that our act generates. So, in Villain 4, when we posit a complaint against (2) based on death, we are not assigning this complaint to anyone. We are simply taking into account that, if you choose (2), there is a one-in-two chance that this act will generate an ex post complaint based on death. ${ }^{17}$

\section{III.C. Ex Post MC}

As I mentioned before, Otsuka's proposal is not quite the right way to apply MC ex post. We can see this by considering a slightly more complicated case. Suppose that in

Villain 5: A villain has kidnapped $\mathrm{C} 1$ and $\mathrm{C} 2$. He will either (1) impose a fifty-unit burden on $\mathrm{C} 1$, or (2) flip a coin to decide whether to impose a ninety-eight- or a ninety-nine-unit burden on $\mathrm{C} 2$. You must choose which.

\footnotetext{
${ }^{16}$ Ibid., p. 86 .

${ }^{17} \mathrm{I}$ take it that by presenting ex post MC in this way, we avoid the second set of objections that Frick presses against this view in "Contractualism and Social Risk," pp. 194-201.
} 
I take it that you are morally required to choose (1), imposing a fifty-unit burden on $\mathrm{C} 1$ in order to spare $\mathrm{C} 2$ from a burden of roughly twice the size. On Otsuka's proposal, however, MC implies otherwise. If we take the ex post complaints that might be generated by (2) and discount each by the probability of it being generated, the strongest resulting complaint has strength 49.5. Since the strongest probability-discounted complaint against (1) is fifty, it follows, on this way of applying $\mathrm{MC}$, that you are morally required to choose (2).

I suggest that the proper way to apply MC ex post is as follows. We consider each possibility that might result from an act, take the strongest ex post complaint in each possibility, discount this complaint by the probability of this possibility obtaining, and then sum the results. The final result is the expected strongest ex post complaint of the act. We are then morally required to act in the way that minimizes the expected strongest ex post complaint.

In Villain 5, there are two possibilities that might result from (2): either C2 will have an ex post complaint of strength ninety-eight, or he will have an ex post complaint of strength ninety-nine. If we take these complaints, discount each by the probability that it is generated, and then sum the results, we get a complaint of strength 98.5. This is the expected strongest ex post complaint of (2). Since this complaint is almost twice as strong as the expected strongest ex post complaint of (1), ex post MC correctly implies that you are morally required to choose (1).

As we have just seen, the modified proposal departs from Otsuka's proposal in cases like Villain 5. But these proposals have the same implications, and apply in roughly the same way, in cases like Villain 2 and Villain 4, where there is only one ex post complaint that might be generated by each of the acts available to us. In what follows, we need consider 
only these simpler cases, so the difference between the modified proposal and Otsuka's proposal will not matter.

\section{Against Ex Post MC}

In the previous section, I tried to clarify what it means to apply $\mathrm{MC}$ ex post, and I explained how ex post MC avoids the objection that I pressed against ex ante MC. In this section, I argue that ex post MC must be rejected, because there are other cases involving risk in which it has implausible implications. I begin by responding to a risk-based objection to ex post $\mathrm{MC}$ suggested by Frick. I then present what seems to me a stronger objection.

\section{IV.A. Frick's Objection to Ex Post MC}

In the course of defending an ex ante version of MCweak, which I argued against in section

2, Frick presses an objection against ex post MC. He asks us to consider the following case. ${ }^{18}$

Virus: A terrible virus threatens one million young children. If we do nothing, the virus will kill all of them. We must choose between mass producing one of two vaccines (capacity constraints prevent us from producing both). Vaccine 1 is certain to save every child's life, but the vaccine does not offer complete protection, so each child will end up with one paralysed leg. Vaccine 2 is risky. It gives each child a 0.999 chance of surviving the virus completely unharmed, but for every child, there is a 0.001 chance that the vaccine will be ineffective, in which case the child will die. So we can expect that, if we choose Vaccine 2, around one thousand of the children will die.

\footnotetext{
${ }^{18}$ Ibid., pp. 181-82.
} 
Frick thinks that we are morally required to choose Vaccine 2, even though, if we do, around one thousand of the children will die. In defense of this judgment, he writes,

In real life, we often impose social risks that closely resemble that of choosing Vaccine 2 . Thus, it is commonly deemed morally unproblematic to systematically inoculate young children against certain serious but nonfatal childhood diseases where there is a remote chance of fatal side effects from the inoculation itself. But this is not because it is unlikely that inoculation will ever lead to disaster for some unlucky children. Given the large number of children inoculated each year, it is a statistical certainty that some number of them will develop fatal complications. ${ }^{19}$

Frick then argues that while ex ante MC is compatible with the claim that we are morally required to choose Vaccine 2, ex post MC is not. He argues as follows. It is better to face a one-in-a-thousand chance of death than to lose the use of a leg. So it is in the ex ante interest of each child that we choose Vaccine 2. So each child has an ex ante complaint against Vaccine 1 and no ex ante complaint against Vaccine 2. So ex ante MC implies that we are morally required to choose Vaccine 2 . But choosing Vaccine 2 would almost certainly generate a number of ex post complaints based on death. Since each of these complaints would be much stronger than an ex post complaint based on losing the use of a leg, ex post MC implies that we are morally required to choose Vaccine 1.

I think there are at least two ways for proponents of ex post $\mathrm{MC}$ to answer this objection.

First, they could adopt an ex post version of PAMC and hold that a complaint against losing the use of a leg is sufficiently close in strength to a complaint against death for PAMC

\footnotetext{
${ }^{19}$ Ibid., pp. 185-86.
} 
to permit the aggregation of these complaints. ${ }^{20}$ It is plausible that one million complaints against losing the use of a leg together outweigh one thousand complaints against death, so ex post PAMC is compatible with the claim that we are morally required to choose Vaccine 2. Frick might respond to this suggestion by reducing the burden that Vaccine 1 imposes on each of the children until the ex post complaint that would be generated by Vaccine 1 is no longer close in strength to the ex post complaint that would be generated by Vaccine 2. But once the burden imposed by Vaccine 1 is sufficiently reduced, it will be much less clear that we are morally required to choose Vaccine 2.

Second, recall that to avoid a version of the objection that I pressed against ex ante MC, Frick suggested adopting an ex ante version of MCweak. Proponents of ex post MC could avoid Frick's objection by making the same move. ${ }^{21}$ That is, they could adopt an ex post version of MCweak. According to this view, when every alternative to an act has a stronger expected strongest ex post complaint, this gives us a pro tanto moral reason to perform this act. As Frick emphasizes, this pro tanto moral reason could be outweighed by other pro tanto moral reasons, such as those deriving from aggregative or consequentialist considerations. Since it is plausible that the aggregative and consequentialist moral reasons in favor of choosing Vaccine 2 would outweigh any complaints-based moral reason in favor of choosing Vaccine 1, ex post MCweak is compatible with the claim that we are morally required to choose Vaccine 2.

IV.B. The Main Objection to Ex Post MC

\footnotetext{
${ }^{20}$ Voorhoeve defends a version of PAMC on which these complaints would indeed be sufficiently close in strength. See Voorhoeve, “How Should We Aggregate Competing Claims?,” pp. 70-75.

${ }^{21}$ I owe this suggestion to Jonathan Quong.
} 
I think that there is a stronger risk-based objection to ex post MC. I will now present three cases that together illustrate this objection.

Suppose that in

Villain 6: A villain has kidnapped $\mathrm{C} 1$. He will either (1) cut one hand off $\mathrm{C} 1$, or (2) run a lottery that gives $\mathrm{C} 1$ a one-in-a-billion chance of death. You must choose which.

I take it that you are morally required to choose (2), exposing $\mathrm{C} 1$ to a tiny chance of death to spare him from losing a hand. For ex post MC to capture this judgment, an ex post complaint based on losing a hand discounted by probability one must be stronger than an ex post complaint based on death discounted by probability one in a billion.

Suppose next that in

Villain 7: A villain has kidnapped one billion children. He will either (1) cut one hand off each child, or (2) randomly select and kill one of the children. You must choose which.

It is not obvious what you should do in this case. But ex post MC implies that you are morally required to choose (1), for (2) is certain to generate an ex post complaint based on death, and that complaint is clearly stronger than an ex post complaint based on losing a hand.

Here comes the problem. Suppose that in

Villain 8: A villain has kidnapped one billion children. For each child, the villain will either (1) cut one hand off this child, or (2) give this child a ticket for a lottery with 
one billion unique tickets. You must choose between these options for each child in turn. You know that, after you have chosen for all of the children, the villain will randomly select one of the one billion lottery tickets and then kill any child who has the corresponding ticket.

For each child, it is certain that choosing (1) will generate an ex post complaint based on losing a hand, and there is a one-in-a-billion chance that choosing (2) will generate an ex post complaint based on death. We have seen, from Villain 6, that an ex post complaint based on losing a hand discounted by probability one is stronger than an ex post complaint based on death discounted by probability one-in-a-billion. So ex post MC implies that, for each child, you are morally required to choose (2). But choosing (2) rather than (1) for each child is equivalent to choosing that the villain randomly select and kill one of the children rather than cut one hand off each child. And that is the same choice that ex post MC condemned in Villain 7. So ex post MC is inconsistent, in the sense that it has different implications across cases that seem in all morally relevant respects equivalent.

The more general problem is this: ex post MC implies that we can be morally required to make a choice $A$ rather than a choice $B$, and yet be morally required to make a series of choices $C$ rather than a series of choices $D$, even when we know that making $C$ rather than $D$ is in all morally relevant respects equivalent to making $B$ rather than $A$. Put another way, ex post $\mathrm{MC}$ violates the following principle of consistency: if a moral view condemns act $X$, it should condemn any series of acts that is in all morally relevant respects equivalent to $X{ }^{22}$ It might seem that this objection can be avoided by adopting ex post PAMC. If we hold that an ex post complaint based on losing a hand is sufficiently close in strength to an ex post complaint based on death for PAMC to permit the aggregation of complaints in Villain

\footnotetext{
${ }^{22}$ I am grateful to an anonymous editor for suggesting this way of putting the point.
} 
7, and we also hold that one billion ex post complaints based on losing a hand together outweigh one ex post complaint based on death, then ex post PAMC implies that you are morally required to choose (2) in Villain 7, which is consistent with the implication that you are morally required to choose (2) for each child in Villain 8. However, we can block this response by reducing the burden that the villain is threatening to impose on each child from the loss of a hand to something much smaller, such as a broken finger, so that ex post PAMC no longer permits the aggregation of complaints in Villain 7. And if an ex post complaint based on the reduced burden is weaker than an ex post complaint based on death discounted by one-in-a-billion, we can just increase the number of children involved in these cases, so that the probability of death for each child becomes negligible. These revisions would also block a response to the objection that appeals to ex post MCweak.

\section{Against Hybrid MC}

I have now raised risk-based objections to both ex ante and ex post MC. It is natural to wonder whether a hybrid of these views could avoid these objections. ${ }^{23}$ According to the simplest hybrid view, which we can call MChybrid, we have a pro tanto moral reason to act in the way that minimizes the strongest ex ante complaint, and we also have a pro tanto moral reason to act in the way that minimizes the expected strongest ex post complaint.

There are a number of problems with this hybrid view, but to save space, I will mention just one. This view is vulnerable to the objection that I raised for ex ante MCweak. Recall Villain 3.

\footnotetext{
${ }^{23}$ James briefly considers a hybrid view in “Contractualism's (Not So) Slippery Slope,” pp. 273-74.
} 
Villain 3: A villain has kidnapped $\mathrm{C} 1$ and one billion other children. He will either (1) break three of C1's fingers, or (2) randomly select one of the other children and break four of his fingers. You must choose which.

I take it that you are morally required to choose (1), imposing three broken fingers on $\mathrm{C} 1$ to spare another child from four broken fingers. MChybrid implies otherwise. It implies that you have a very strong ex ante complaints-based reason to choose (2), since a complaint against certainly having three fingers broken is much stronger than a complaint against a one-in-abillion chance of having four fingers broken. And though it also implies that you have an ex post complaints-based reason to choose (1), this reason is much weaker, since an ex post complaint against having four fingers broken is only slightly stronger than an ex post complaint against having three fingers broken. Since the ex ante complaints-based reason to choose (2) is much stronger than the ex post complaints-based reason to choose (1), MChybrid implies that you are morally required to choose (2).

A proponent of MChybrid could avoid this objection by holding that ex post complaints-based reasons are generally stronger than ex ante complaints-based reasons, but this move, as well as seeming rather ad hoc, would leave the view vulnerable to a version of the objection that I pressed against ex post MC. I conclude that MChybrid is not a promising view.

\section{Reconsidering Aggregation}

That completes my critique of MC. I argued that we should reject ex ante MC, because it implies that we are morally required to do what we know will be very bad for many people rather than what we know will be much less bad for a few people whenever we have sufficiently low credence about whom the former people are. And I argued that we should 
reject ex post MC, because it implies that we can be morally required to make a choice $A$ rather than a choice $B$, and yet be morally required to make a series of choices $C$ rather than a series of choices $D$, even when we know that making $C$ rather than $D$ is in all morally relevant respects equivalent to making $B$ rather than $A$.

I suspect that any plausible nonaggregative view would have to be structurally very similar to MC. It might focus not on minimizing the strongest complaint, but instead on minimizing the greatest loss, or on satisfying the strongest claim to be helped. But such departures from MC would be largely cosmetic. If that is right, we can expect cases involving risk to pose serious problems not just for $\mathrm{MC}$, but also for nonaggregative views more generally. We should therefore reconsider the prospects for aggregative views.

As we saw in the introduction, aggregative views tend to have counterintuitive implications in cases in which we must choose between imposing large burdens on each of a few people and imposing small burdens on each of many. Recall Scanlon's illustration.

Transmitter Room: Jones has suffered an accident in a TV broadcasting station and is receiving extremely painful electric shocks. If you turn off the power, a huge number of viewers will miss the second half of the World Cup final.

Intuitively, you are morally required to turn off the power, no matter how many viewers there are. But aggregative views imply that, if there are enough viewers, you are morally required to leave the power on, for the burden imposed on Jones will be less than the sum of the burdens that would be imposed on each of the viewers.

I suggest that, in the absence of a viable nonaggregative view, we can plausibly accept the implications that aggregative views have in cases like Transmitter Room. To form intuitions about these cases, we need to imagine progressively larger groups of people. But, 
as proponents of aggregative views have pointed out, our imaginations are not good at distinguishing between very large quantities. ${ }^{24}$ When we try to imagine, for example, one billion people, the image in our mind is likely to be roughly the same as when we try to imagine one million. If our imaginations could more reliably distinguish between very large quantities, our intuitions about cases like Transmitter Room might be different. So we should be much less confident in these intuitions than we are in our intuitions about other cases.

It might be objected that, if we cannot be confident in our intuitions about cases involving very large groups of people, we cannot be confident in our intuitions about my villain cases. But while these cases do involve very large groups of people, they do not require us to imagine all of these people. To form intuitions about these cases, we need only imagine the people who would actually be affected by our choosing each of the options available to us, and that requires us to imagine only a relatively small number of people. For example, though Villain 2 involves over ten billion children, we can form intuitions about this case just by comparing an outcome in which $\mathrm{C} 1$ loses a hand with an outcome in which ten children die. We can easily imagine these outcomes, and it is obvious which is worse.

It might now be objected that at least Villain 7 and Villain 8 require us to imagine very large groups of people, for they require us to imagine an outcome in which each of one billion children loses a hand. However, my argument involving Villain 7 and Villain 8 does not rely on our intuitions about how we should act in these cases. Instead, it relies on the judgment that these cases are in all morally relevant respects equivalent.

I do not deny that the implications that aggregative views have in cases like Transmitter Room are counterintuitive. But given our limited ability to imagine these cases,

\footnotetext{
${ }^{24}$ For example, Michael Huemer, “In Defence of Repugnance,” Mind 117 (2008): 899-933, at pp. 907-10; John Broome, Weighing Lives (Oxford: Oxford University Press, 2004), pp. 56-57; and Norcross, “Comparing Harms."
} 
the counterintuitiveness of these implications is not a decisive reason to reject these views. And if I am right about the prospects for nonaggregative views, we may have no choice but to embrace aggregation despite these implications.

\section{Why Complaints Still Matter}

I have argued that we should reject MC and embrace aggregation. Since complaints were introduced to support antiaggregative intuitions, it might seem that once we embrace aggregation, we should forget about complaints. In this section, I argue that we should not. Though aggregative views have traditionally focused on the sum of benefits minus burdens, they can also focus on the sum of complaints. And we should prefer those that do, for only they can respect two morally important facts: the separateness of persons and the unity of the individual.

It will be useful to have some new labels. If an aggregative view focuses on the sum of benefits minus burdens, we can call it traditional. If an aggregative view focuses on the sum of complaints, we can call it complaints-based. As with MC, complaints-based aggregative views can be applied either ex ante or ex post.

\section{VII.A. A Dilemma for Traditional Aggregative Views}

I will now present a dilemma for traditional aggregative views. In doing so, I build on an argument originally presented by Michael Otsuka and Alex Voorhoeve. ${ }^{25}$

Suppose that in

\footnotetext{
${ }^{25}$ Michael Otsuka and Alex Voorhoeve, "Why It Matters that Some Are Worse Off Than Others: An Argument against the Priority View," Philosophy \& Public Affairs 37 (2009): 171-99.
} 
Treatment 1: $\mathrm{C} 1$ and $\mathrm{C} 2$ are aged ten. They have a terrible disease that requires immediate treatment. If you do (1), they will both live to exactly twenty-five. If you do (2), either C1 will live to exactly twenty-five and C2 will live to exactly twenty, or C1 will live to exactly twenty-five and C2 will live to exactly thirty-one, with an equal chance of each. ${ }^{26}$

Since C1 will live to twenty-five regardless of whether you do (1) or (2), we can ignore him for the moment. If you choose (1), C2 will live to twenty-five. If you choose (2), C2 will live to either twenty or thirty-one, with an equal chance of each. Suppose, for the sake of argument, that each year of life is a roughly equal benefit. Given this supposition, (2) gives C2 a slightly greater expected benefit than (1), for it gives him an expected 15.5 years of life as opposed to fifteen. Given standard assumptions about rationality, because (2) gives C2 a slightly greater expected benefit than (1), it would be rational for $\mathrm{C} 2$ to choose that you do (2). And very plausibly, because it would be rational for C2 to choose that you do (2), and because no one else has any stake in your decision, it is at least morally permissible for you to do (2).

Suppose next that in

Treatment 2: $\mathrm{C} 1$ and $\mathrm{C} 2$ are aged ten. They have a terrible disease that requires immediate treatment. If you do (1), they will both live to exactly twenty-five. If you do (2), either C1 will live to exactly twenty and C2 will live to exactly twenty-five, or $\mathrm{C} 1$ will live to exactly twenty-five and $\mathrm{C} 2$ will live to exactly thirty-one, with an equal chance of each.

\footnotetext{
${ }^{26}$ Treatment 1 and Treatment 2 are adapted from cases used by Derek Parfit, which are adapted from cases used by Otsuka and Voorhoeve. See Parfit, “Another Defence of the Priority View,” Utilitas 24 (2012): 399-440.
} 
In this case, doing (2) rather than (1) is significantly better for C2, since it gives him a 0.5 chance of living to thirty-one rather than twenty-five without any prospect of a loss.

However, doing (2) rather than (1) is significantly worse for $\mathrm{C} 1$, since it gives him a 0.5 chance of living to twenty rather than twenty-five without any prospect of a gain. I take it that giving the larger benefit to $\mathrm{C} 2$ does not justify giving the smaller benefit to $\mathrm{C} 1$, so you are morally required to do (1).

If we agree that it is morally permissible for you to do (2) in Treatment 1 and that you are morally required to do (1) in Treatment 2 , we must reject traditional aggregative views. To see why, consider the following four outcomes.
A. C1 lives to twenty-five $\mathrm{C} 2$ lives to twenty-five
B. C1 lives to twenty-five C2 lives to twenty
C. C1 lives to twenty-five C2 lives to thirty-one
D. C1 lives to twenty C2 lives to twenty-five

In Treatment $1,(1)$ will bring about $A$, and (2) will bring about either $B$ or $C$, with an equal chance of each. In Treatment 2, (1) will bring about $A$, and (2) will bring about either $C$ or $D$, with an equal chance of each. So traditional aggregative views can capture our judgment about the difference between these cases only if we hold that the distribution of benefits and burdens in $B$ is somehow morally better than the distribution in $D$. And that would be very implausible, for it would imply that benefits and burdens to $\mathrm{C} 1$ have greater moral importance than benefits and burdens to $\mathrm{C} 2$.

To avoid this objection, proponents of traditional aggregative views could deny that it is morally permissible for you to choose (2) in Treatment 1 . And to defend this denial, they 
could plausibly claim that C2 living to twenty-five rather than twenty is of greater moral importance than him living to thirty-one rather than twenty-five. ${ }^{27}$ However, this response comes at a significant intuitive cost, for it implies that it is morally wrong for you to do what it would be rational for $\mathrm{C} 2$ to choose that you do, even though no one else has any stake in your decision.

So traditional aggregative views face a dilemma. Either they imply that it is morally permissible for you to do (2) in Treatment 1 , in which case they have the very counterintuitive implication that it is morally permissible for you to do (2) in Treatment 2, or they imply that you are morally required to do (1) in Treatment 2, in which case they have the very counterintuitive implication that you are morally required to do (1) in Treatment 1.

The more general dilemma is this: either traditional aggregative views imply that we are morally required to distribute benefits and burdens across different people in a way that seems appropriate only when distributing benefits and burdens within a single life, or they imply that we are morally required to distribute benefits and burdens within a single life in a way that seems appropriate only when distributing benefits and burdens across different people. If a view falls on the first horn of this dilemma, we can say that it fails to respect the separateness of persons - it wrongly implies that whenever giving someone a prospect of a gain $\mathrm{G}$ is intuitively sufficient to justify exposing the same person to a risk $\mathrm{R}$, giving someone $\mathrm{G}$ is sufficient to justify exposing someone else to R. If a view falls on the second horn of this dilemma, we can say that it fails to respect the unity of the individual — it wrongly implies that giving someone a prospect of a gain $\mathrm{G}$ is sufficient to justify exposing

\footnotetext{
${ }^{27}$ This claim is supported by Prioritarianism. See Parfit, "Equality and Priority," pp. 212-14.
} 
the same person to a risk R only when giving someone $\mathrm{G}$ is intuitively sufficient to justify exposing someone else to $\mathrm{R}^{28}$

\section{VII.B. How Ex Ante Complaints-Based Views Can Avoid the Dilemma}

I will now argue that ex ante complaints-based views, whether aggregative or nonaggregative, can simultaneously respect both the unity of the individual and the separateness of persons.

\section{Recall Treatment 1.}

Treatment 1: $\mathrm{C} 1$ and $\mathrm{C} 2$ are aged ten. They have a terrible disease that requires immediate treatment. If you do (1), they will both live to exactly twenty-five. If you do (2), either C1 will live to exactly twenty-five and C2 will live to exactly twenty, or C1 will live to exactly twenty-five and C2 will live to exactly thirty-one, with an equal chance of each.

Since (2) gives C2 a slightly greater expected benefit than (1), C2 has an ex ante complaint against (1) and no ex ante complaint against (2). Since C1 will live to twenty-five regardless of whether you do (1) or (2), there is no opposing ex ante complaint to consider. So ex ante complaints-based views imply that you are morally required to do (2).

More generally, in cases in which only one person is affected by what we do, the only possible ex ante complaints are against acts that go against the ex ante interest of the one

\footnotetext{
${ }^{28}$ As John Rawls argues, Utilitarianism fails to respect the separateness of persons. See Rawls, A Theory of Justice (Cambridge, Mass.: Harvard University Press, 1999), pp. 19-24. Prioritarianism fails to respect the unity of the individual. See Otsuka and Voorhoeve, "Why It Matters That Some Are Worse Off Than Others," pp. 171-78. I owe the phrase "the unity of the individual" to Thomas Porter, "In Defence of the Priority View," Utilitas 24 (2012): 349-64.
} 
person. So in these cases, ex ante complaints-based views always imply that we are morally required to act in the way that gives the one person the greatest expected benefit, which is also what it would be rational for the one person to choose that we do.

Next, recall Treatment 2.

Treatment 2: $\mathrm{C} 1$ and $\mathrm{C} 2$ are aged ten. They have a terrible disease that requires immediate treatment. If you do (1), they will both live to exactly twenty-five. If you do (2), either C1 will live to exactly twenty and C2 will live to exactly twenty-five, or C1 will live to exactly twenty-five and C2 will live to exactly thirty-one, with an equal chance of each.

Again, C2 has an ex ante complaint against (1), since (2) gives him a 0.5 chance of living to thirty-one rather than twenty-five without any prospect of a loss. But now $\mathrm{C} 1$ has an opposing ex ante complaint, since (2) gives him a 0.5 chance of living to twenty rather than twenty-five without any prospect of a gain. So to determine what ex ante complaints-based views imply about this case, we must decide which of these opposing complaints is stronger.

Plausibly, the strength of a person's complaint against an act is determined in part by the difference between how well off she can expect to be given this act and how well off she can expect to be given the act that would be best for her, with the strength of the complaint increasing as this difference increases. If this difference were the sole determinant of the strength of a complaint, C2 would have a stronger complaint against (1) than C1 has against (2), since the difference for $\mathrm{C} 2$ is three years while the difference for $\mathrm{C} 1$ is only 2.5 years. However, as proponents of MC have argued, this difference should not be the sole determinant of the strength of a complaint. Plausibly, the strength of a person's complaint against an act is also determined by how well off she can expect to be given this act, with the 
strength of the complaint increasing the worse off she can expect to be. Since C2 can expect to live to twenty-five given (1) while $\mathrm{C} 1$ can expect to live to only 22.5 given (2), this second consideration strengthens the complaint of $\mathrm{C} 1$ relative to the complaint of $\mathrm{C} 2$.

When determining the strength of a complaint, we can plausibly give this second consideration significant weight. We can then conclude that, on the whole, $\mathrm{C} 1$ has a stronger complaint against (2) than C2 has against (1). So ex ante complaints-based views are compatible with the claim that you are morally required to do (1) in Treatment 2. And more importantly, they are compatible with this claim even though they also imply that you are morally permitted to do (2) in Treatment 1.

More generally, in cases in which more than one person is affected by what we do, there can be opposing ex ante complaints, and the strongest complaint can be against the act that would give the greatest expected benefit. So ex ante complaints-based views are compatible with the claim that, in these cases, what we are morally required to do is not always what would maximize the greatest expected benefit. So these views are compatible with the claim that the appropriate way to distribute benefits and burdens across different people is different from the appropriate way to distribute benefits and burdens within a single life.

In other words, ex ante complaints-based views can simultaneously respect both the unity of the individual and the separateness of persons. That gives us a strong reason to favor ex ante complaints-based aggregative views over traditional aggregative views.

\section{VII.C. Why Ex Post Complaints-Based Views Cannot Respect the Unity of the Individual} Unlike ex ante complaints-based views, ex post complaints-based views cannot respect the unity of the individual. I will now explain why.

Recall Treatment 1. 
Treatment 1: $\mathrm{C} 1$ and $\mathrm{C} 2$ are aged ten. They have a terrible disease that requires immediate treatment. If you do (1), they will both live to exactly twenty-five. If you do (2), either C1 will live to exactly twenty-five and C2 will live to exactly twenty, or $\mathrm{C} 1$ will live to exactly twenty-five and $\mathrm{C} 2$ will live to exactly thirty-one, with an equal chance of each.

It is not obvious what ex post complaints-based views imply about this case. If you do (2), there is a one-in-two chance that $\mathrm{C} 2$ will live to twenty, in which case he will have an ex post complaint based on living to twenty rather than twenty-five. If you do (1), C2 will live to twenty-five, but we do not know how long he would have lived for otherwise, so it is not obvious what ex post complaint he will have.

I suggest that we determine the ex post complaint that $\mathrm{C} 2$ will have given (1) by comparing how well off he will be given (1) with how well off he can expect to be given (2). If you do (2), he will live to either twenty or thirty-one, with an equal chance of each. So his life expectancy given (2) is 25.5 . So, on this way of determining ex post complaints, doing (1) will give $\mathrm{C} 2$ an ex post complaint against living to twenty-five rather than 25.5.

So to determine what ex post complaints-based views imply about this case, we must compare a complaint against living to twenty rather than twenty-five discounted by one in two with a complaint against living to twenty-five rather than 25.5. Presumably, a complaint against living to twenty rather than twenty-five discounted by one in two is roughly equivalent to a complaint against living to twenty rather than 22.5. Since that complaint is stronger than a complaint against living to twenty-five rather than 25.5 , ex post complaintsbased views imply that you are morally required to do (1). They thereby conflict with our judgment that you are at least morally permitted to do (2). 
Of course, this argument relies on my suggested way of determining the ex post complaint that $\mathrm{C} 2$ will have given (1). But I cannot see a plausible alternative to this suggestion. And really it should be unsurprising that ex post complaints-based views fail to respect the rational preferences of $\mathrm{C} 2$, for his rational preferences are determined by his ex ante perspective, and ex post complaints-based views ignore that perspective.

More generally, in cases in which only one person is affected by what we do, ex post complaints-based views sometimes imply that we are morally required to act against the rational preferences of the one person. They thereby fail to respect the unity of the individual. That gives us a strong reason to favor ex ante complaints-based aggregative views over ex post complaints-based aggregative views. It also gives us another reason to reject ex post MC.

\section{Conclusion}

Aggregative views tend to have counterintuitive implications in cases like Transmitter Room. Many philosophers have responded by rejecting aggregative views, focusing on complaints, and accepting some version of MC. If my arguments in sections 2 through 5 are sound, we must reject $\mathrm{MC}$, for it has implausible implications in certain cases involving risk.

I suspect that cases involving risk will pose serious problems not just for $\mathrm{MC}$, but also for nonaggregative views more generally. Fortunately, if my arguments in section 6 are sound, we can plausibly embrace aggregation despite the counterintuitive implications that aggregative views have in cases like Transmitter Room. Though these implications are counterintuitive, our intuitions about these cases are not reliable, because our imaginations are not good at distinguishing between very large quantities.

Since complaints were introduced to support antiaggregative intuitions, it might seem that once we embrace aggregation, we should forget about complaints. If my arguments in 
section 7 are sound, we should not. Though aggregative views have traditionally focused on the sum of benefits minus burdens, they can also focus on the sum of complaints. And we should prefer those that do, for only they can respect two morally important facts: the separateness of persons and the unity of the individual. 